\title{
Researching design solutions for frames of buildings in case of increased seismic intensity in specific zones
}

\author{
Leonid Panasyuk ${ }^{1}$, Galina Kravchenko ${ }^{1}$, and Elena Trufanova ${ }^{1, *}$ \\ ${ }^{1}$ Don State Technical University, 344000, 1 Gagarina Square, Rostov-on-Don, Russia
}

\begin{abstract}
Currently, there is a trend to increase the estimated seismic hazard for construction sites. With this, the buildings erected under the previously valid norms have the lesser hazard resistance. The present article inquiries into an issue of how the design solutions affect the safety of the building change under the increased seismic intensity. This article represents the calculation of a building without regard to seismic intensity and the same was made for a rate-7 seismic intensity district. Recommendations on enhancement of building frame elements reinforcement and an evaluation of strain stress behavior changes for the building frame are given herein.
\end{abstract}

\section{Introduction}

Pursuant to the Decision of the Russian Federation Government No. 1033, the Construction Rules SP 14.13330.2014 Construction in seismic regions have come into force from July 01, 2015. Taking Table 1 Estimated Seismic Hazard of Construction Sites of the SP 14.13330.2014 into account, the grounds of Rostov Region falling under the category III increase the rate of seismic intensity of the sites to 7 points.

Due to the calculation norms for braced frames or full frames without collar beams with reinforced concrete diaphragm plates, stiffening cores, or steel tie bolts in the rate- seismic intensity zones, the height limit shall not exceed 57 meters (16 storeys).

The difficulty of designing the buildings with the account to seismic exposures lies in determining geological features of the site and obtaining initial geological information.

Seismic motion of ground is a random process. Specific methods of seismic exposure and system response referencing are used.

\section{Problem definition}

The task is to provide for the seismic resistance of edifices due to the optimal selection of structural design with an account given to sufficient accuracy of seismic loads. The seismic loads belong to the class of dynamic exposures.

\footnotetext{
*Corresponding author: el.trufanova@mail.ru
} 
Seismic calculation of an edifice can be notionally divided into the following stages:

1. Referencing of the initial parameters of the building frame;

2. Creation of a finite element model on the basis of slab-and-rod scheme;

3. Determination of the geological features of the construction site;

4. Introduction of seismological information;

5. Calculation of stresses within the edifice, its supports, footing, etc., under the combination of seismic and other stresses;

6. Assessment of the seismic resistance.

\section{Research methods}

Two models of two-bay frame-solid-cast residential house with underground parking lot and offices on the ground floor were considered in order to evaluate the seismic influence on strain stress behaviour of the multi-storeyed building frame.

Model engineering of the special frame based on the slab-and-rod scheme with the use of finite elements method was undertake in Ing+ software complex in order to solve the task set forth above. Raft foundation, intermediate and floor slabs, walls and diaphragm plates were modelled with triangular shell elements with 18 degrees of freedom, and quadrangular shell elements with 24 degrees of freedom. The columns were modeled with spatial rods having 12 degrees of freedom. The structural design was elaborated with regard to anchorage of columns, diaphragm plates and walls into the solid-cast raft foundation.

The first model is a spatial slab-and-rod finite element scheme comprising over two and a half million finite elements. It takes the joint operation of two building bays separated by an expansion joint, and ductility of piled foundation into account. Fig.1shows the finite element model representing the distribution of materials (force constants) along the building frame.

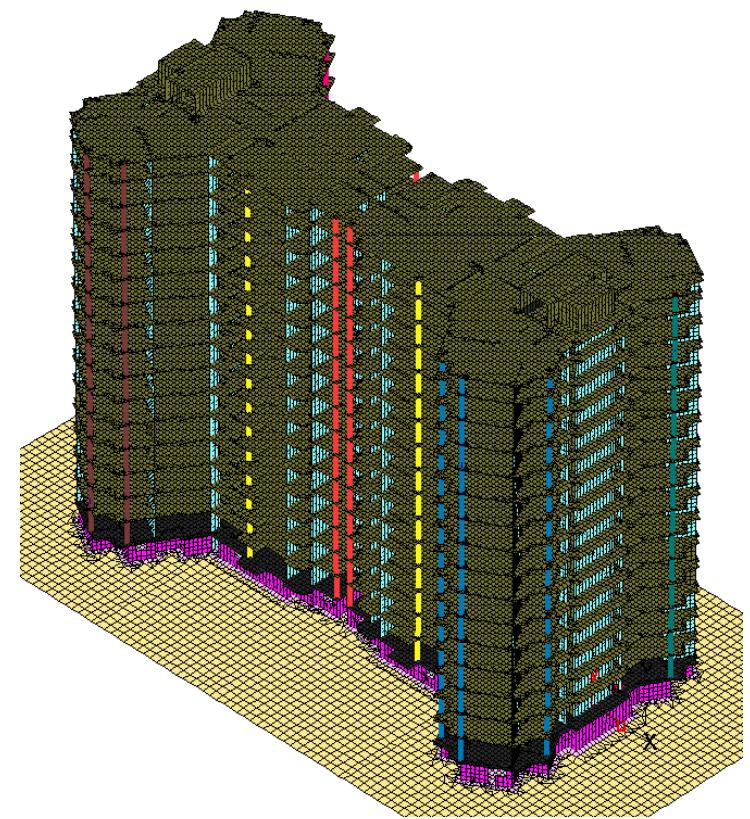

Fig. 1.Finite element model with materials distribution. 
A peculiarity of modelling lies in taking the mutual influence of bays under different variants of staging of erection thereof into account. Only several variants of erection sequence have been considered. The first variant had foreseen the erection of the bay 1 , then the aby 2. The second variant had foreseen the reverse order of erection. The third variant had considered the simultaneous erection of both bays. It was only natural that different variants of mutual influence entailed different design solutions for reinforcement. By using KLEN-MKD complex, it was possible to select an optimal calculated reinforcement variant providing for edifice stability under any erection consequence.

When harmonizing the results obtained for constructive parts of the same type (e.g., normal floor intermediate slabs), it must be taken into account that the finite element meshes within the different fragments of the model may not match. The following algorithm was thus used. The first mesh from the harmonization list prepared by the user is taken as the basic mesh on which the harmonization results are reflected. Then, the calculated reinforcement results obtained for other slabs are transferred onto the first one. In case that the finite element meshes do not match, interpolation of the value in the point matching the basic mesh nod is necessary.

Whereas the shell elements with two types of geometry, i.e., triangle and convex quadrangle, are used for modelling of intermediate and floor slabs, walls and diaphragm plates, we will consider below an interpolation of calculated reinforcement in the finite element point described as k., jq (notional description of reinforcement with arbitrary direction is given as $f(x, y))$.

Standard linear interpolation with the values of calculated reinforcement on three vertexes is used for the triangular element.

In case of the quadrangular element, standard bilinear interpolation with the values of calculated reinforcement on four vertexes $f(x, y)=a_{0}+a_{1} x+a_{2} y+a_{3} x y$ can be successfully applied if the element under consideration is quadrangular.

The mentioned interpolation has three positive aspects:

Linear variation of the function on the edges of the element;

Non-linear variation of the function within the element;

The value of the function within the element does not exceed the limits of the value in two nods: $f(x, y) \in\left[\min \left\{f_{i}\right\}, \max \left\{f_{i}\right\}\right]$.

Nevertheless, such interpolation is hindered in case of an arbitrary convex quadrangle. It is thus proposed to interpolate the value of the function within the arbitrary convex quadrangular element by using the reflection of such arbitrary convex quadrangle onto the square (Fig. 2).

The mapping of coordinates $(\mathrm{x}, \mathrm{y}) \sim(\mathrm{a}, \mathrm{b})$ is thereby performed. Interpolation shall be made relative of the local coordinates $(\mathrm{a}, \mathrm{b}): f(\alpha, \beta)=a_{0}+a_{1} \alpha+a_{2} \beta+a_{3} \alpha \beta$.

It is not difficult to prove that such mapping is mutually identical but in the general case a direct line is not reflected onto another direct line, and thus, such mapping is not affine. Local coordinates within the quadrangle $(\mathrm{a}, \mathrm{b})$ are obtained by drawing axes between two opposite sides dividing such opposite sides proportionally. 


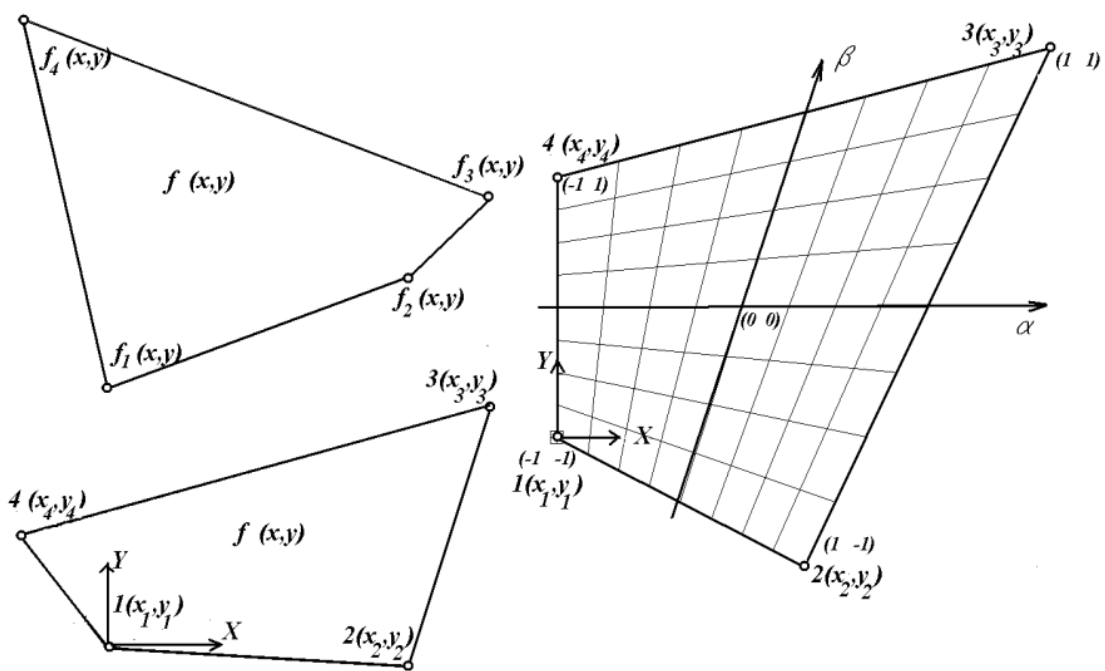

Fig. 2.Interpolation of calculated reinforcement within the rectangular finite element.

Following is the relation between the local and the general Cartesian coordinates $(\mathrm{x}, \mathrm{y})$ :

$$
\left\{\begin{array}{l}
x(\alpha, \beta)=0.25 \times\left((1-\alpha)(1-\beta) x_{1}+(1+\alpha)(1-\beta) x_{2}+(1+\alpha)\right. \\
y(\alpha, \beta)=0.25 \times\left((1-\alpha)(1-\beta) y_{1}+(1+\alpha)(1-\beta) y_{2}+(1+\alpha)\right. \\
o r \\
x(\alpha, \beta)=\sum_{i=1}^{4} \xi_{i}(\alpha, \beta) x_{i}, \quad y(\alpha, \beta)=\sum_{i=1}^{4} \xi_{i}(\alpha, \beta) y_{i}, \\
\xi_{1}(\alpha, \beta)=\frac{1}{4}(1-\alpha)(1-\beta), \xi_{2}(\alpha, \beta)=\frac{1}{4}(1+\alpha)(1-\beta), \\
\xi_{3}(\alpha, \beta)=\frac{1}{4}(1+\alpha)(1+\beta), \xi_{4}(\alpha, \beta)=\frac{1}{4}(1-\alpha)(1+\beta)
\end{array}\right.
$$

In order to identify the mutual dependence, a system (1) must be solved with regard to the unknown $(a, b)$. Final resulting equations are shown in the system (2).

$$
\left\{\begin{array}{l}
f(\alpha, \beta)=a_{0}+a_{1} \alpha+a_{2} \beta+a_{3} \alpha \beta \\
\left.\mid \begin{array}{cccc}
1 & \alpha_{1} & \beta_{1} & \alpha_{1} \beta_{1} \\
1 & \alpha_{2} & \beta_{2} & \alpha_{2} \beta_{2} \\
1 & \alpha_{3} & \beta_{3} & \alpha_{3} \beta_{3} \\
1 & \alpha_{4} & \beta_{4} & \alpha_{4} \beta_{4}
\end{array}\right] \times\left(\begin{array}{l}
a_{0} \\
a_{1} \\
a_{2} \\
a_{3}
\end{array}\right)=\left(\begin{array}{c}
f_{1} \\
f_{2} \\
f_{3} \\
f_{4}
\end{array}\right), A_{\alpha \beta} a=f \\
a=A_{\alpha \beta}^{-1} f, \\
f(\alpha, \beta)=\left(\begin{array}{lll}
1 & \alpha & \beta
\end{array}\right) \times A_{\alpha \beta}^{-1} \times f
\end{array}\right.
$$


Expression for local coordinates $(a, b)$ is given in (3) where the dependence for $b$ is symmetrical to a with the exchange $x \sim y$.

$$
\alpha=\left[\begin{array}{l}
\left(y_{1}-y_{2}+y_{3}-y_{4}\right) x+\left(x_{2}+x_{4}-x_{3}-x_{1}\right) y+x_{3} y_{1}-2 x_{4} y_{1}+x_{4} y_{2}-x_{1} y_{3}+2 x_{1} y_{4}-x_{2} y_{4}+ \\
\sqrt{4\left(x_{2}\left(-y+y_{1}\right)+x_{1}\left(y-y_{2}+x\left(y_{2}-y_{1}\right)\right)\left(x_{14} y_{23}+x_{32} y_{14}\right)\right)+} \\
\sqrt{\left[\left(-y_{1}+y_{2}-y_{3}+y_{4}\right) x+\left(x_{3}-x_{4}+x_{1}-x_{2}\right) y-x_{3} y_{1}+x_{4} y_{2}-2 x_{1} y_{2}+x_{1} y_{3}-2 x_{2} y_{1}-x_{2} y_{4}\right]^{2} /} \\
\left(2\left(x_{34} y_{12}-x_{12} y_{34}\right)\right)
\end{array}\right]
$$

Dynamic calculation results are shown on Figure 3. The range of frequencies and forms of oscillations is limited to 30 forms.
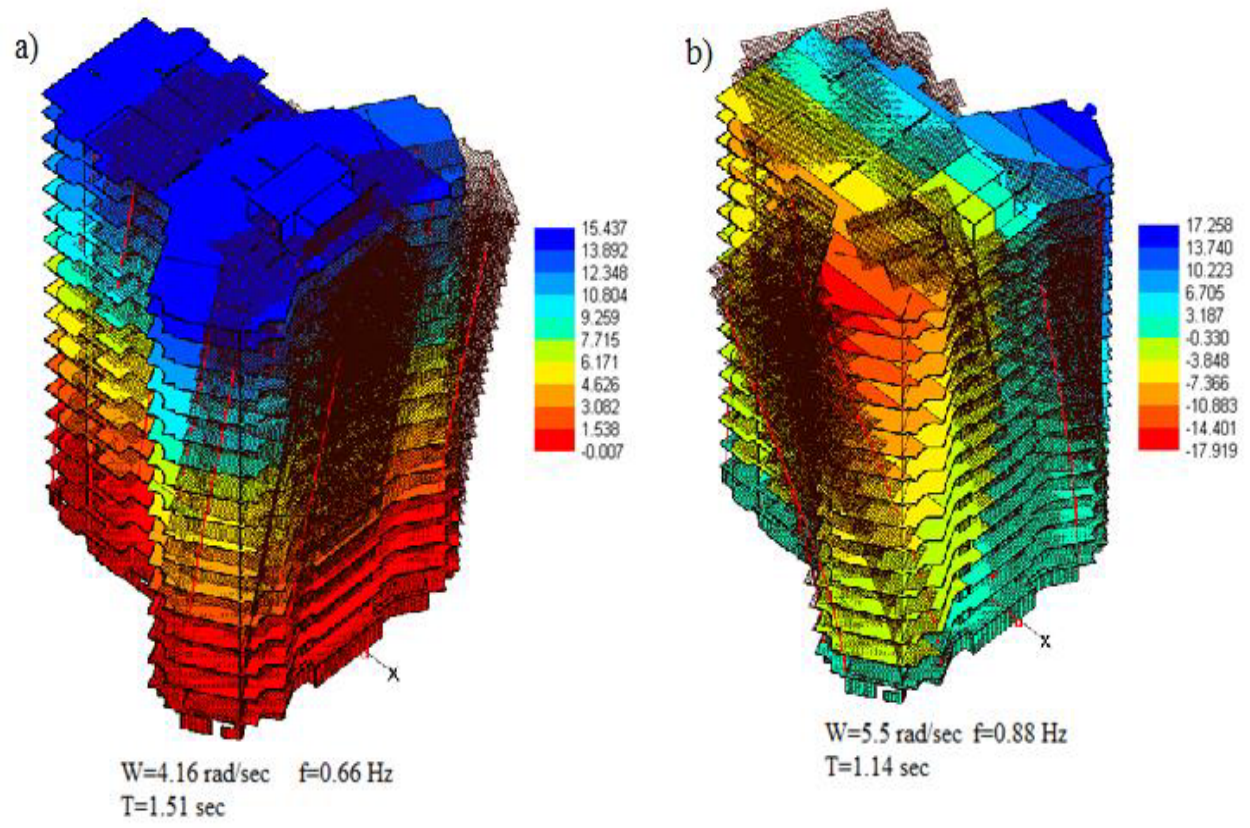

Fig. 3.Forms of oscillations: a) transitional oscillation along $X$ axis $(\mathrm{mm})$; b) torsional oscillation $(\mathrm{mm})$.

The second model varies by the presence of the section containing calculation of seismic load with the rate 7 under the spread of a seismic wave in three directions.

\section{Analysis of results}

Results obtained for intermediate slab at the mark 9.000 without consideration of seismic load were used to compare the strain stress behavior of the building frame elements, with rate 7 seismic load (Figures4, 5). These results are represented graphically as colourise zones. Reinforcement calculation has been made with both and without consideration of edifice erection history, and with and without consideration of mutual influence of the bays.

Together with this, the reinforcement calculation results were recorded as DXF files for each variant, and then the KLEN-MKD system read the corresponding fragment $\mathrm{s}$ for 
various calculation variants, determined the reinforcement maximum in various directions for each nod, and represented the results as isozones and as text.

The results are shown as the maximum of reinforcement surveying for each variant in every nod within the calculation domain by the specially designed KLEN-MKD software.

It means that the calculation results for reinforcement represented in this report admittedly satisfy all calculation variants.

The calculation was made under the estimated combinations of forces (ECF).

The parameters of estimated combinations of forces are given as printouts of dialogue screens of ECF parameters referencing under consideration of 17 variants of loading (static and dynamic - wind pulse and seismic loads).

The reinforcement selection parameters are shown below as printouts of dialogue screens of parameters referencing.
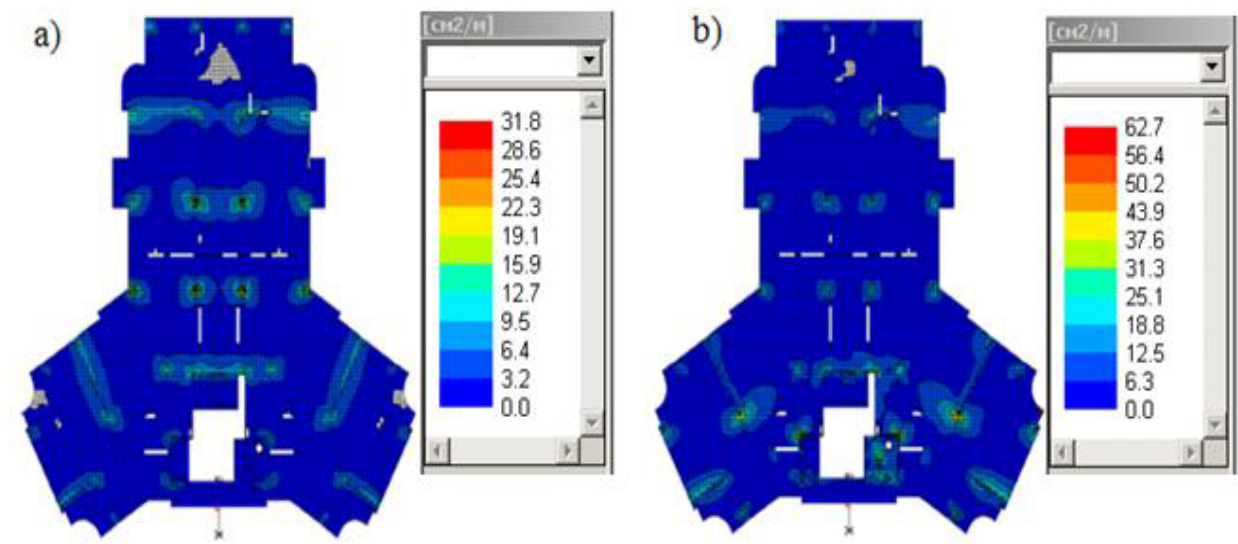

Fig.4. Lateral top reinforcement of the first layer $\left(\mathrm{sm}^{2} / \mathrm{m}\right)$ : a)model $\left.1 ; \mathrm{b}\right)$ model 2.

Results for intermediate slab reinforcement at the mark 9.000 of the two-bay framesolid-cast residential house with underground parking lot and offices on the ground floor both with and without rate 7 seismic load consideration are represented in the Table 1.
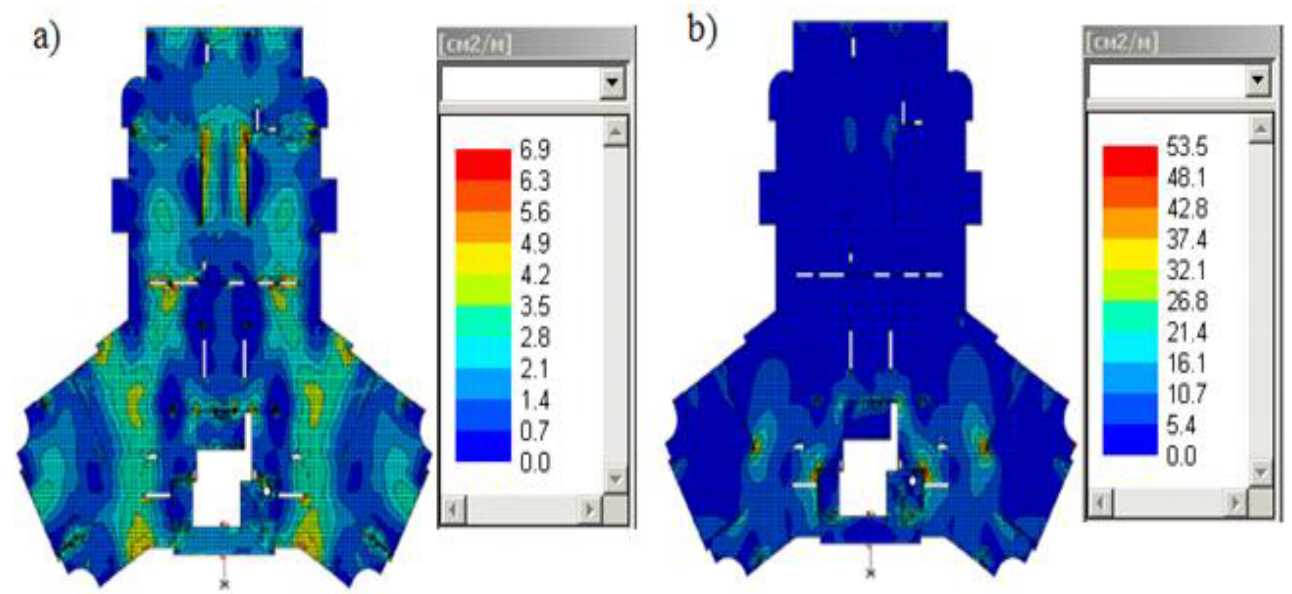

Fig.5.Lateral bottom reinforcement of the second layer ( $\left.\mathrm{sm}^{2} / \mathrm{m}\right)$ : a) model1; b) model 2 . 
Table 1.Results for intermediate slab reinforcement.

\begin{tabular}{|c|c|c|c|c|}
\hline $\begin{array}{c}\text { No. } \\
\text { pos. }\end{array}$ & $\begin{array}{c}\text { Reinforcement demand } \\
\text { for intermediate slab }\end{array}$ & $\begin{array}{c}\text { Reinforcement } \\
\text { mass, kg, grade: } \\
\text { A400 (w/o seismic } \\
\text { load) }\end{array}$ & $\begin{array}{c}\text { Reinforcement } \\
\text { mass, kg, grade: } \\
\text { A400 (with } \\
\text { seismic load) }\end{array}$ & $\begin{array}{c}\text { Reinforcement } \\
\text { enhancement with } \\
\text { consideration of } \\
\text { seismic load, \% }\end{array}$ \\
\hline 1 & Top, 1 layer & 1090 & 2720 & $250 \%$ \\
\hline 2 & Top, 2 layer & 1210 & 2370 & $196 \%$ \\
\hline 3 & Bottom, 1 layer & 944 & 2570 & $272 \%$ \\
\hline 4 & Bottom, 2 layer & 1060 & 2250 & $212 \%$ \\
\hline 5 & Lateral & 596 & 6450 & $1082 \%$ \\
\hline 6 & Sum - top layers $1+2$ & 2300 & 5090 & $221 \%$ \\
\hline 7 & Sum - bottom layers $1+2$ & 2004 & 4820 & $241 \%$ \\
\hline 8 & Sum - top + bottom & 4304 & 9910 & $230 \%$ \\
\hline 9 & Sum - lateral + traversal & 4900 & 16360 & $334 \%$ \\
\hline
\end{tabular}

\section{Conclusions}

Analysis of the methods revealed that the increase of seismic hazard form rate 6 to rate 7 entails an increase of calculated reinforcement of the building frame. Thus, the aggregate reinforcement of the intermediate slab at the $9000 \mathrm{~min}$ the two-bay frame-solid-cast residential house was increased by 3.34 times.

Various structural components have different increase factor for calculated reinforcement enhancement. It is hence impossible to a priori recommend uniform correction factors for reinforcement in respect to basic variant.

\section{References}

1. A.V. Perelmuter, V.I. Slivker, Predictive Models of Edifices and Possibility of Analysis Thereof (Steel, Kazan, 2002)

2. V. Simbirkin, Modern Building Materials 1, 6(2004)

3. G.M. Kravchenkop, A.A. Kazantsev, D.A. Shamitko, Determination of Optimal Parameters for Rod and Slab Systems (Warsaw, 2006)

4. R.W. Clough, J.Penzien, Dynamics of Structures (McGraw-Hill,New York, 1993)

5. E.K. Agakhanov, Technical Sciences 1, 22(2013)

6. E.K. Agakhanov, G.M. Kravchenko, et. al.. Technical Sciences 1, 34 (2014)

7. G.M. Kravchenko, E.V. Trufanova, D.S. Kostenko, Technical Sciences 1-2, 35-36 (2015)

8. G.M. Kravchenko, E.V.Trufanova, A.V. Dolzhenko, Natural and Technical Sciences 1, 21(2013)

9. V.L. Lebedev, V.A. Semenov, P.Y. Semenov, et. al. Theses of IX Russian National Conference on Earthquake-Resistant Construction and Seismic Zoning 1, 12(2011)

10. T.V. Zhirnova, A.S. Simonyan, V.A. Semenov, Optimization of Calculated FE Meshes for Spatial Edifices (TsNIIProyekt, Moscow, 2001)

11. G.M. Kravchenko, A.P. Korobkin, E.V. Trufanova, et. al., Science Time 1, 65(2014)

12. E.K. Agakhanov, N.S. Magomedeminov, Technical Sciences 1, 12(2006)

13. L.N. Panasyuk, G.M. Kravchenko, E.V. Trufanova, Scientific Review 2, 31(2014) 